\title{
AVALIAÇÃO MECÂNICA DE MATERIAIS COMPÓSITOS DE MATRIZ CIMENTÍCIAS REFORÇADOS COM FIBRAS DE POLI(TEREFTALATO DE ETILENO) *
}

Priscila Alves da Silva Machado ${ }^{1}$ Luciano da Silva Delgado ${ }^{2}$ André Luiz Bastos Pessoa ${ }^{3}$ Lorena Alves da Silva Machado ${ }^{4}$

\section{Resumo}

A busca por pesquisas que provem soluções e inovações que utilizam parte de tais resíduos vem ganhando grande destaque. O poli (tereftalato de etileno) é um polímero termoplástico, e é o material base para produção de embalagens plásticas que são comercializadas mundialmente. Sabe-se que é de grande volume os resíduos sólidos provenientes de tais embalagens plásticas. Com o objetivo de solucionar um problema ambiental e verificar a viabilidade técnica, foram fabricados em proporções de $0 \%, 5 \%, 10 \%$ e $15 \% \mathrm{~m} / \mathrm{m}$, materiais compósitos de base cimentícias reforçados com fibras de poli (tereftalato de etileno) provenientes de resíduos de garrafas plásticas (PET), posteriormente amostras passaram por caracterizações mecânicas. Destacou-se um aumento das resistências a compressão axial e diametral do material produzido com fabricação de adição de poli(tereftalato de etileno). Tais resultados referente a resistência foram positivos, propondo assim a utilização do polímero na composição de novos compósitos.

Palavras-chave: Compósitos Cimentícios; Polímeros; Poli(tereftalato de etileno).

\section{MECHANICAL EVALUATION OF MATERIALS COMPOSITE OF CEMENTITIOUS MATRICES REINFORCED WITH POLY(ETHYLENE TEREPHTHALATE) FIBERS} Abstract

The search for research that provides solutions and innovations that use part of such waste has been gaining prominence. Poly(ethylene terephthalate) is a thermoplastic polymer, and is the base material for the production of plastic packaging that are marketed worldwide. It is known that large scale solid wastes from such plastic packages. With the objective of solving an environmental problem and verifying the technical feasibility, $0 \%, 5 \%, 10 \%$ and $15 \% \mathrm{~m} / \mathrm{m}$, cementitious base materials reinforced with poly(ethylene terephthalate) fibers were manufactured of plastic bottle waste, samples were then subjected to mechanical characterization. Was noted an increase in the axial and diametral compression strength of the material produced with addition of poly(ethylene terephthalate). These results concerning the resistance were positive, thus proposing the use of the polymer in the composition of new composites.

Keywords: Cementitious Composite; Polymers; Poly(ethylene terephthalate).

1 Graduanda em Engenharia Civil, Universidade do Estado de Minas Gerais, João Monlevade, Minas Grais, Brasil.

2 Graduação em Física, Mestre em Ciências Naturais e da Saúde, Professor de Ensino Superior, Universidade do Estado de Minas Gerais, João Monlevade, Minas Grais, Brasil.

3 Graduando em Engenharia Metalúrgica, Universidade do Estado de Minas Gerais, João Monlevade, Minas Grais, Brasil.

4 Graduanda em Engenharia Civil, Universidade do Estado de Minas Gerais, João Monlevade, Minas Grais, Brasil. 


\section{INTRODUÇÃO}

O crescimento populacional e avanço da tecnologia facilitou a vida da humanidade, porém contribuiu para crescimento de impactos ambientais. Destaca-se como um dos maiores fatores problemáticos ao meio ambiente a imensa quantidade de resíduos sólidos produzido pela população, e novos meios de reutilização de materiais ganham destaque na sociedade atual e apresentam papel fundamental para solucionar referente problema.

Ao decorrer da ECO-92 e a definição da Agenda 21, destacou-se a imensa necessidade de se implementar um eficiente sistema de gestão ambiental para os resíduos sólidos, e o incentivo a novas tecnologias de reaproveitamento que atendem ao tripé da sustentabilidade [1].

Como alternativa significante na produção de bens de consumo, novos materiais servem de subsídios para a produção de pesquisas de caráter inovador e que podem ser aplicadas em prol da sustentabilidade.

Materiais cimentícios são originados de cerâmicas, que por sua vez são compostos entre elementos metálicos e não-metálicos, tais materiais são tipicamente isolantes à passagem de eletricidade e de calor, e são resistentes a altas temperaturas e ambientes rudes. E com relação ao comportamento mecânico, cerâmicas são duras, porém muito frágeis [2].

Materiais poliméricos são compostos por polímeros originados de matéria orgânica que são quimicamente baseados em carbono, hidrogênio, e outros elementos não metálicos. Estes materiais possuem características tipas de baixas densidades e são extremamente flexíveis [3].

Os compósitos são materiais reconstituídos a partir de um ou mais materiais dispersos numa matriz e chamados de carga de reforço ou carga de enchimento [2]. O objetivo da combinação de dois tipos de materiais é a combinação das características individuais de seus componentes, para que apresente melhor desempenho estrutural em condições específicas de uso [3].

No material de matriz cimentícia, as fibras poliméricas geram dois efeitos importantes à primeira de controlar a fissuração e microfissuração, melhorando a tenacidade e conferindo ductilidade [4]. Esses efeitos ocorrem porque o aumento da quantidade de fibras resulta no aumento da quantidade de pontes de transferência de tensões nas fissuras [5].

Quanto à degradação por longo tempo, as fibras poliméricas quando comparadas a outros tipos de fibras ganham destaque pois não sofrem ataques de microorganismos, como é o caso por exemplo da fibra vegetal; corrosão, no caso de fibras de aço; degradação em meio alcalino do cimento, no caso de fibras vegetal e de vidro.

Os materiais compósitos fabricados de combinações de polímeros e materiais cerâmicos são os mais importantes. Os materiais baseados em cimento Portland são considerados como materiais cerâmicos por apresentarem propriedades típicas a este grupo de materiais, como, por exemplo, alta rigidez, fragilidade, baixa resistência à tração e tendência de fissuração por secagem [6].

O poli(tereftalato de etileno) é um material polimérico, e é a composição básica das embalagens de garrafas plásticas comercializadas mundialmente, conhecidas como PET, após consumo e representa $20 \%$ do volume de lixo depositado nos aterros sanitários [7]. 
Quanto às propriedades mecânicas, os polímeros são caracterizados por possuírem ductilidade variável, moderada resistência à tração e baixo módulo de elasticidade [3].

A presente pesquisa teve com o objetivo a produção de compósitos de matriz cimentícia à base de cimento Portland e fibras de reforço a base de poli(tereftalato de etileno) provenientes de garrafas descartáveis pós consumo recolhidas na cidade de João Monlevade - Minas Gerais e a análise técnica das propriedades mecânicas do material produzido relacionados a resistência.

\section{MATERIAIS E MÉTODOS}

Foi realizada revisão bibliográfica relacionadas aos materiais utilizados para produção do compósito, análise experimental de amostras de compósitos produzidos. Todos os procedimentos experimentais foram executados no Laboratório de Materiais de Construção da Universidade do Estado de Minas Gerais, Unidade João Monlevade, seguindo como base literária as normas técnicas vigentes da Associação Brasileira de Normas Técnicas - ABNT.

A seguinte pesquisa, partiu-se na confecção de diferentes tipos de amostras de material compósito, diferenciados entre si, pela quantidade de fibras de poli (tereftalato de etileno).

Para a produção das amostras, utilizou-se cimento, areia natural e água na para a produção da matriz, e como reforço, fibras de poli (tereftalato de etileno).

\subsection{Cimento Portland}

O cimento Portland é obtido a partir da calcinação e clinquerização de uma mistura de calcário e argila em proporções adequadas. De acordo com a ABNT 14656(2001), os principais compostos químicos do cimento Portland é mostrado na tabela (1).

Tabela 1: Composição Química do cimento Portland
\begin{tabular}{lll} 
Nome do composto & Abreviação & Teor médio em \% \\
\hline Óxido de cálcio & $\mathrm{CaO}$ & $60-67$ \\
\hline Dióxido de sílica & $\mathrm{SiO} 2$ & $17-25$ \\
\hline Oxido de aluminó & $\mathrm{Al} 2 \mathrm{O} 3$ & $3-8$ \\
\hline Oxido de ferro & $\mathrm{Fe} 2 \mathrm{O} 3$ & $0,5-6$
\end{tabular}

Fonte: Associação brasileira de Normas Técnicas

O cimento Portland utilizado na composição da matriz cimentícia foi o CP-IV 32 RS. A tabela (2) apresenta as características físicas do mesmo.

Tabela 2: Caracterização do cimento

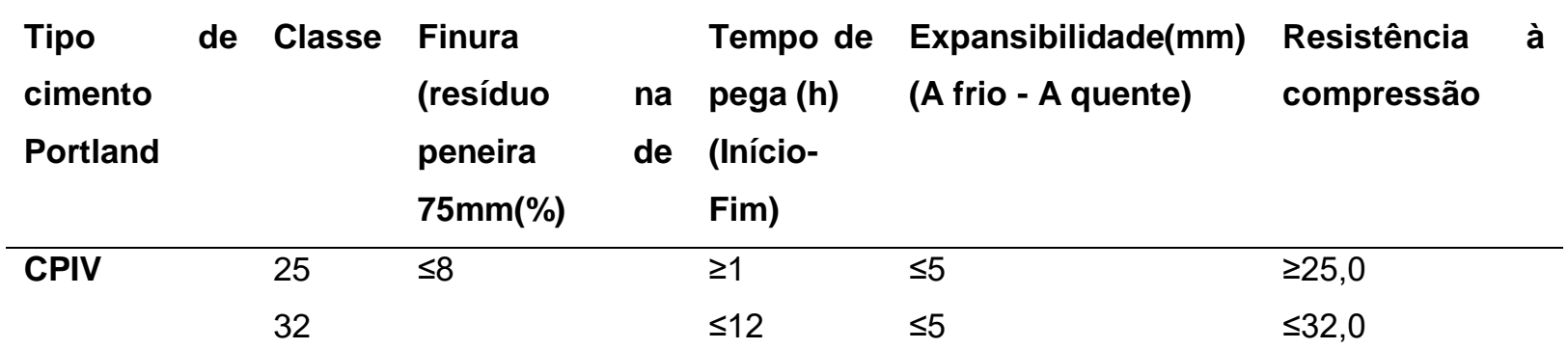

Fonte: Associação Brasileira de Cimento Portland 


\subsection{Areia}

A areia utilizada para a produção das amostras é proveniente do Rio Doce, e é classificada como areia fina (1,85 Módulo de finura).

Agregados miúdos são aqueles formados por partículas menores que 4,75 mm, variando entre $75 \mu \mathrm{m}$ (peneira $\mathrm{n}^{0}$ 200) a 4,75 mm [8]. A Figura (1) representa a curva granulométrica da areia de estudo onde no eixo das abscissas em escala logarítmica representa-se a abertura das peneiras, e o eixo das ordenadas os valores das porcentagens retidas nessas.

Figura 1. Curva Granulométrica da areia

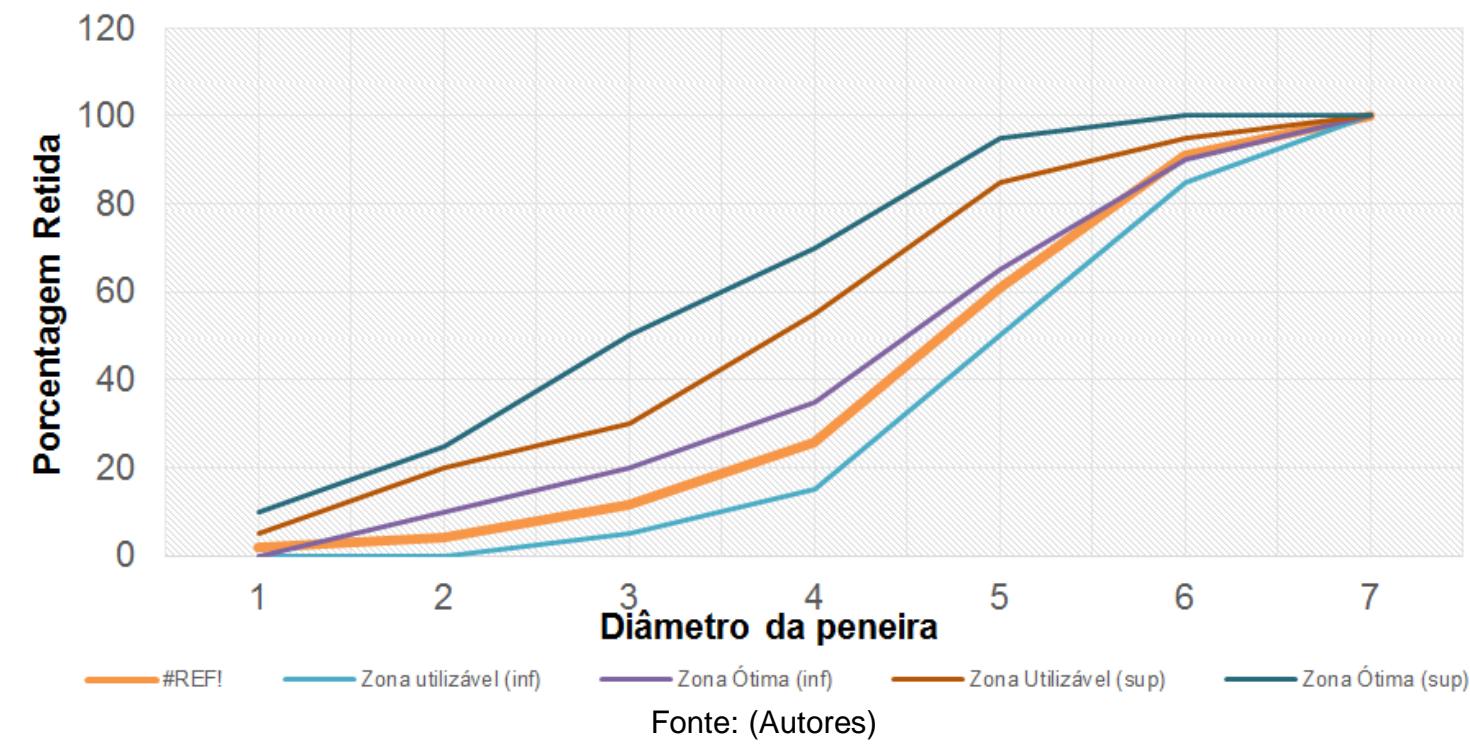

Conforme a Figura (1), a curva granulométrica da areia analisada está dentro da zona utilizável, porém a maior parte da curva não estava dentro da zona ótima de utilização, só até a peneira $4,75 \mathrm{~mm}$ foi notório que o agregado estava dentro dos limites ótimos. Foi determinado da massa específica da areia, agregado miúdo e a massa unitária, resultados são apresentados na tabela (3). A areia pode ser classificada como normal, pois, sua massa específica está entre 2000 kg/m3 e 3000 $\mathrm{kg} / \mathrm{m}[9]$.

Tabela 3: Características da areia

\begin{tabular}{lll}
\hline Material & Massa específica $\left(\mathbf{g} / \mathrm{cm}^{3}\right)$ & Massa Unitária $\left(\mathbf{g} / \mathrm{cm}^{3}\right)$ \\
\hline Areia & 2,61 & 1,55 \\
\hline
\end{tabular}

\subsection{Poli(tereftalato de etileno)}

O Poli(tereftalato de etileno) utilizado em forma de fibras de reforço para produção do compósito foi proveniente de embalagens de garrafas pós consumo. Antes de serem incorporadas a matriz cimentícia, as mesmas passaram por processo de lavagem com água corrente e foram secas em estufa a temperatura de $(25 \pm 0,5){ }^{\circ} \mathrm{C}$ 
por 24 horas. As garrafas de poli(tereftalato de etileno), foram processadas em triturador, originando fibras de comprimento médio de $(2,3-0,2) \mathrm{cm}$.

\subsection{Confecção dos compósitos e moldagem dos corpos-de-prova}

A dosagem da matriz foi adotada pelo traço utilizado foi de 1:2:0,4 (material cimentício: areia: água/material cimentício em peso) [5].

Foram utilizados proporções mássicas de $0 \%, 5 \%, 10 \%$ e $15 \%$ de substituição do cimento por de fibras. A tabela (4) mostra as características dos traços.

Tabela 4: Característica da dosagem

\begin{tabular}{lllcl}
\hline Amostra & Cimento $\mathbf{( g )}$ & Areia $\mathbf{( g )}$ & $\begin{array}{l}\text { Fibras } \\
\text { poli(tereftalato } \\
\text { de etileno) } \mathbf{( g )}\end{array}$ & Água $(\mathbf{m l})$ \\
\hline ISENTA & 2000 & 4000 & 0 & 800 \\
\hline $\mathbf{5 \%} \mathbf{~} / \mathbf{m}$ & 1900 & 4000 & 100 & 800 \\
\hline $\mathbf{1 0} \mathbf{m} / \mathbf{m}$ & 1800 & 4000 & 200 & 800 \\
\hline $\mathbf{1 5 \%} \mathbf{m} / \mathbf{m}$ & 1700 & 4000 & 300 & 800 \\
\hline
\end{tabular}

Para a produção da massa, misturou-se os materiais secos (cimento, areia e poli(tereftalato de etileno) por 3 minutos em baixa velocidade (124rpm), em seguida se adicionou-se água e deixou-se misturar por 2 minutos em baixa velocidade, por último, para homogeneizar o material, deixou-se mais 3 minutos em velocidade alta (240rpm). Esse procedimento foi feito em argamassadeira com capacidade de 5L.

O material caracterizado em seu estado fresco e endurecido. No estado seco foi determinado a consistência do material e no estado endurecido as propriedades mecânicas referentes a resistência.

\section{RESULTADOS E DISCUSSÃO}

\subsection{Consistência}

A consistência do material em estado fresco foi determinada de acordo com a norma NBR 7215, em que se utiliza um apoio horizontal liso e totalmente plano, um molde de forma tronco-cônico e o soquete de material metal. Coloca-se três camadas do material com alturas iguais e aplica-se 15,10 e 5 golpes uniformes homogeneamente em cada camada. Posteriormente, o material que ultrapassa a borda é retirado, e alisa-se a parte superior com uma régua. Depois de cheio, o molde tronco-cônico foi retirado, deixando que a mistura se espalhasse na mesa e com auxílio de uma régua mediu-se o diâmetro atingido pelo material. Calculando-se a diferença entre o diâmetro atingido pelo material e o diâmetro do molde [10]. A tabela (5) mostra resultados obtidos em relação ao ensaio de consistência

Tabela 5: Resultados do ensaio de consistência

\begin{tabular}{lc}
\hline Porcentagem de Fibras & Diferença de medidas de diâmetro \\
\hline $\mathbf{0} \%$ & $4,3 \mathrm{~mm}$ \\
\hline $\mathbf{5 \%}$ & $4 \mathrm{~mm}$ \\
\hline $\mathbf{1 0} \%$ & $3,7 \mathrm{~mm}$ \\
\hline $\mathbf{1 5 \%}$ & $2,3 \mathrm{~mm}$ \\
\hline
\end{tabular}


O teor de superplastificante foi determinado através da diferença entre medidas foi menor do que $5 \mathrm{~mm}$ em todas as amostras.

\subsection{Caracterização Mecânica}

Para a caracterização mecânica, as amostras foram submetidas a ensaios de resistência mecânica em equipamento de ensaio universal. $\mathrm{O}$ mesmo transmite ao material uma força máxima de ruptura e gera uma curva tensão-deformação. Através das curvas geradas em ensaios realizados em 7,14 e 28 dias, calcularam-se resistências mecânicas referentes à compressão, à tração referente ao ensaio de compressão diametral, à resistência e a tração por flexão. Neste tópico apresentamse os resultados obtidos nos ensaios mecânicos mencionados anteriormente. Estes dados permitem avaliar as propriedades de resistência do compósito reforçados com fibras de poli(tereftalato de etileno) PET.

\subsection{Resistência a compressão axial}

A Figura (2) mostra os resultados obtidos referentes ao ensaio de resistência à compressão axial, que consiste em determinar a carga máxima de ruptura suportada pelo corpo de prova. Observa-se que o menor valor de resistência à compressão ocorreu na amostra de $15 \% \mathrm{~m} / \mathrm{m}$ de reforçado com fibras de PET e o maior valor ocorreu no compósito com substituição parcial de $5 \% \mathrm{~m} / \mathrm{m}$ de reforço de fibras de PET.

Figura 2. Resistência à compressão axial.

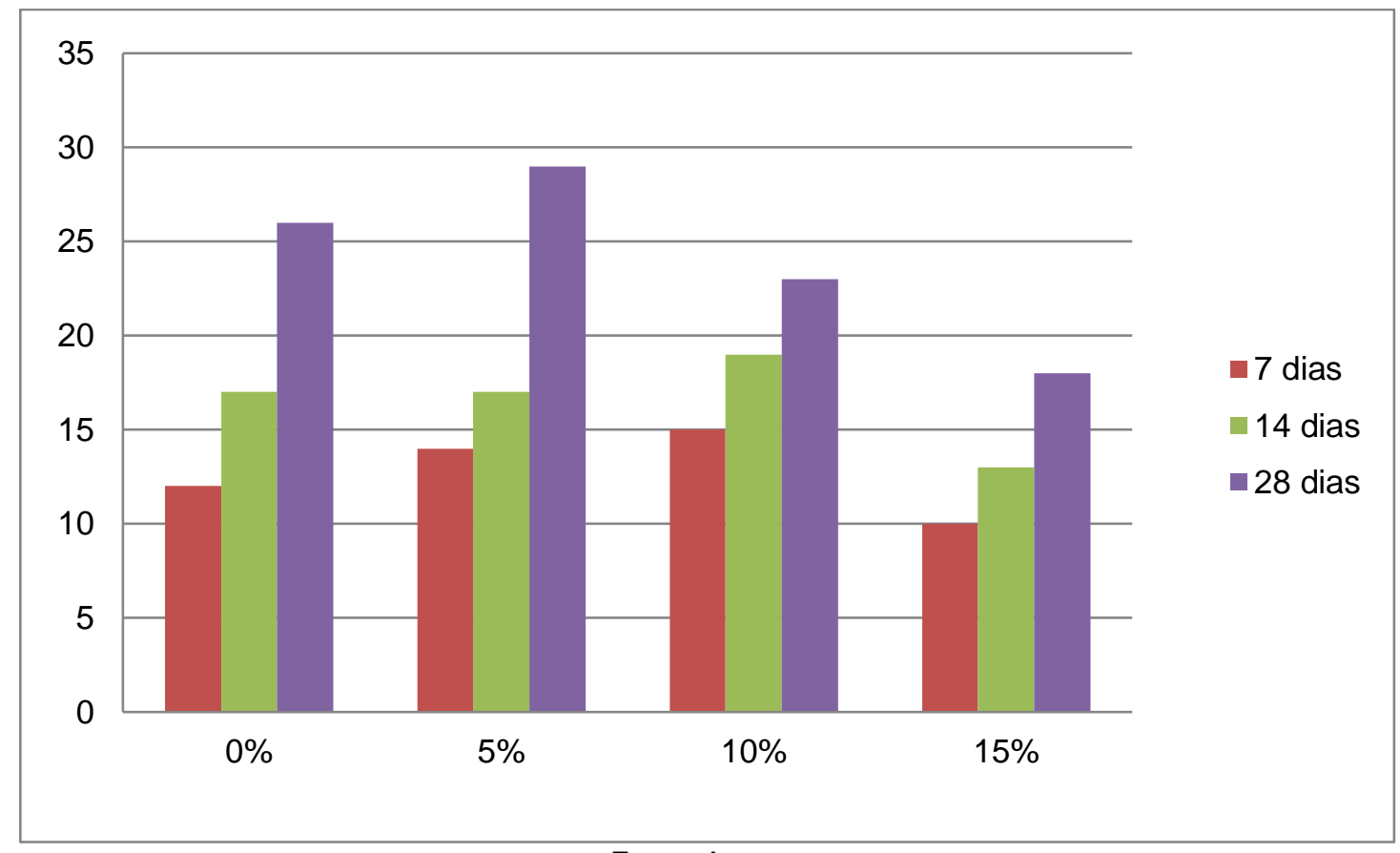

Fonte: Autores

\subsection{Resistências à compressão diametral}


A Figura (3) apresenta dados referentes aos resultados do ensaio à compressão diametral, que determina o valor de resistência à tração. $O$ ensaio é determinado pela ação de duas forças de compressão distribuídas linearmente e diametralmente opostas. Essas ações são fornecidas por uma prensa mecânica, gerando ao longo do diâmetro solicitado, tensões de tração uniformes perpendiculares ao diâmetro do corpo de prova. As forças são aplicadas até que ocorra à ruptura do corpo de prova por tração indireta [12].

Através de resultados obtidos em relação à resistência a compressão diametral, nota-se que amostras com $5 \% \mathrm{~m} / \mathrm{m}$ de reforço de fibras de PET não sofreram perca de resistência após 14 dias em referência as amostras isentas. $E$ nas amostras fabricadas a partir de $10 \% \mathrm{~m} / \mathrm{m}$ sofreram grades perdas referentes à resistência diametral.

Figura 3. Resistência à compressão diametral

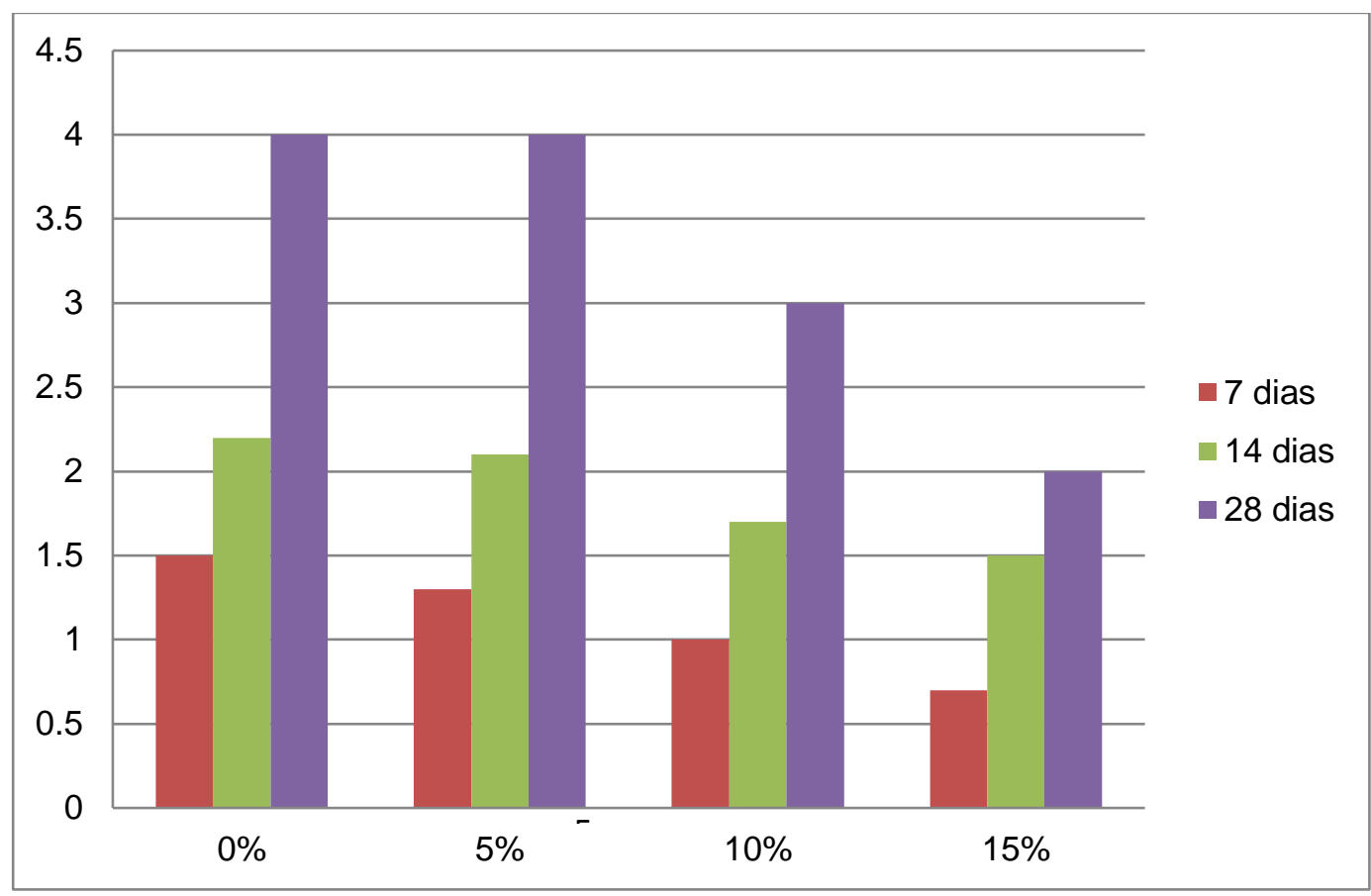

Fonte: Autores

\subsection{Tração por flexão}

A Figura (4) expõe resultados referentes a ensaios de tração por flexão ao quais amostras foram submetidas. Para a realização deste ensaio, um corpo-de-prova de seção prismática é submetido à flexão, com carregamentos em duas seções simétricas, até à ruptura. O ensaio também é conhecido por "carregamento nos terços", pelo fato das seções carregadas se encontrarem nos terços do vão [13].

Tal ensaio mostrou que todas amostras perderam resistência com o aumento do reforço das fibras de poli(tereftalato de etileno), propõe-se que tal diminuição da resistência foi devida por fratura das fibras devido suas posições relativas a matriz cimentícia, ao invés do arrancamento, isso resultou-se numa perca da capacidade das amostras de absorção de energia. 
Figura 4. Resistência à tração por flexão

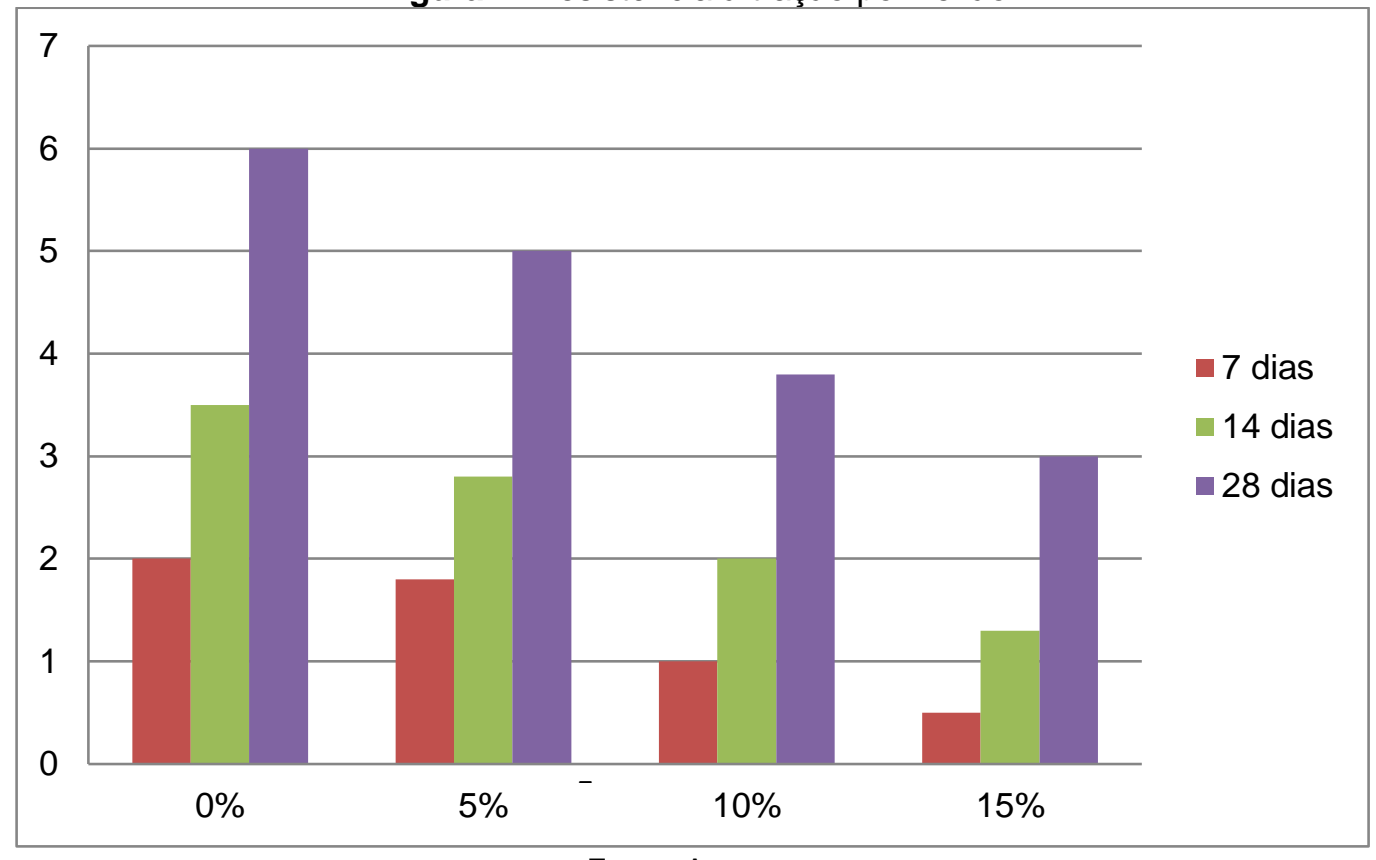

Fonte: Autores.

\section{CONCLUSÃO}

O trabalho proporcionou resultados positivos a todos os objetivos propostos pela pesquisa. Uma característica importante a ser observada nos compósitos é o efeito sinérgico que se observa no sistema, onde as propriedades finais do compósito são uma mistura melhorada das propriedades de seus componentes individualmente.

De acordo com ensaios realizados em laboratórios com amostras nas condições de $5 \% \mathrm{~m} / \mathrm{m}$ de substituição fibra cimento em relação à resistência a compressão axial e a compressão diametral, o emprego de fibras poliméricas de poli(tereftalato de etileno) à formulações de compósitos de matriz cimentícia é tecnicamente viável.

Porém após $5 \% \mathrm{~m} / \mathrm{m}$ de substituição, desencadeou uma queda significativa nas características mecânicas referentes à resistência do compósito produzido.

$\mathrm{E}$ em virtude dos dados obtidos, a porcentagem para emprego das fibras poliméricas de poli(tereftalato de etileno) mais recomentada é a de $5 \% \mathrm{~m} / \mathrm{m}$. Ressalta-se a necessidade de estudo de adição de fibras de poli(tereftalato de etileno) em porcentagens inferiores a $5 \% \mathrm{~m} / \mathrm{m}$.

\section{Agradecimentos}

Agradecimento à Universidade do Estado de Minas Gerais- Campus João Monlevade pelo apoio a pesquisa.

\section{REFERÊNCIAS}


[1] GUNTHER, W.M.R. Minimização de resíduos e educação ambiental. In: SEMINÁRIO NACIONAL DE RESÍDUOS SÓLIDOS E LIMPEZA PÚBLICA, 7. Curitiba, 2000. Anais. Curitiba, 2000.

[2] WOLCOTT, M. P. Production methods and platforms for wood plastics. In: NONWOOD SUBSTITUTES FOR SOLID WOOD PRODUCTS CONFERENCE, 2003, Melbourne: 2003.

[3] CALLISTER Jr., W.D., Ciência e Engenharia dos Materiais, uma Introdução, 7ª Edição, Ed. Guanabara, 2008.

[4] SPECHT, L. P. Comportamento de Misturas Solo-Cimento_fibra Submetidas a Carregamentos Estáticos e Dinâmicos Visando a Pavimentação. 2000. 94 f. Dissertação (Mestrado em Engenharia) Universidade Federal do Rio Grande do Sul, Programa de Pós-Graduação em Engenharia Civil, Porto Alegre, 2000.

[5] BENTUR, A.; MINDESS, S. Fibre Reinforced Cementitious Composites. 2ed. London: Elsevier, 1990.

[6] ARAÚJO, C. T. F. Estudo do Comportamento de Juntas de Argamassa Reforçadas com Fibras de Polipropileno. 94p. Dissertação (Mestrado) Universidade Federal de Alagoas, Maceió, 2005.

[7] SILVEIRA, A. Vantagens da reciclagem. Disponível em: www.vassourapet.com.br. Acesso em: Outubro, 2014.

[8] MEHTA, P. Kumar; MONTEIRO, Paulo J. M. Concreto microestrutura, propriedades e materiais. Rio de Janeiro: Ibracon, 2014

[9] MEHTA, P. K. e MONTEIRO, P. J. M.. Concreto: Estruturas, propriedades e materiais. São Paulo: IBRACON, 2008.

[10] ALVES FIDELIS, M. E.; DE ANDRADE SILVA, F.; DIAS TOLEDO FILHO, $R$. The Influence of Fiber Treatment on the Mechanical Behavior of Jute Textile Reinforced Concrete. Key Engineering Materials v. 600, n. 469474, 2014.

[11] ABNT - Associação Brasileira de Normas Técnicas. NBR 5739: Concreto - Ensaios de compressão de corpos-de-prova cilíndricos. ABNT, Rio de Janeiro, 2007.

[12] ABNT - Associação Brasileira de Normas Técnicas. NBR 7222- Concreto e argamassa - Determinação da resistência à tração por compressão diametral de corpos de prova cilíndricos. ABNT, Rio de Janeiro. 2011.

[13] ABNT - Associação Brasileira de Normas Técnicas. NBR 12142 / MB 3483: Concreto - Determinação da resistência à tração na flexão em corpos-de-prova prismáticos. (Procedimento). Rio de Janeiro, dezembro de 1991. 3 págs. 